\title{
Rotor Angle and Voltage Stability Analysis with Fault Location Identification on the IEEE 9 Bus System
}

\author{
Hafiz Farhaj Khan \\ Department of Electrical Engineering \\ Wah Engineering College \\ University of Wah \\ Wah Cantt, Pakistan \\ farhaj.khan@wecuw.edu.pk
}

\author{
Aamir Hanif \\ Department of Electrical Engineering \\ Wah Engineering College \\ University of Wah \\ Wah Cantt, Pakistan \\ dr.aamirhanif@wecuw.edu.pk
}

\author{
Naveed Anwar \\ Department of Electrical Engineering \\ Wah Engineering College \\ University of Wah \\ Wah Cantt, Pakistan \\ Naveed.anwar@wecuw.edu.pk
}

\begin{abstract}
Transient stability is very imperative in multi-machine interconnected power systems in order to scrutinize and analyze the system's performance and response. Rotor angle stability and voltage stability are studied in this paper. By applying threephase symmetrical faults, the transient stability of the IEEE 9 bus system is studied. A characteristic double hump is analyzed in the response of the generator, which is nearer to the fault location. By analyzing the characteristic double hump, the fault location in a large interconnected power system can be determined. It is shown that, as the fault is cleared, the system takes some finite time to return to its prior state. IEEE 9 bus system is chosen as a test system, which standard parameters. MATLAB Simpower System toolbox is used for load flow and transient stability analysis.
\end{abstract}

Keywords-transient stability; steady state stability; characteristics hump; rotor angle; IEEE 9 bus system

\section{INTRODUCTION}

There are three stages in a power system, generation, transmission, and distribution [1]. In generation, electric power is generated mostly from synchronous machines, which are very sensitive to disturbances [2]. Nowadays, power industries move towards deregulation and competition and electric power systems are becoming increasingly interconnected and sophisticated [3-4]. Loads are tapped off from different locations. A fault at any location in the system can distress the system's performance [5] and under this scenario, transient stability is very significant in designing the electric power system [6]. A power system is designed to maintain continuous power supply to consumers and voltage stability when unwanted events, like short circuits, lightening strokes, etc., occur [7]. Due to these faults, one or many generators can be out of synchronism causing a disproportion between generation and demand [8]. System's stability is the capability of the system to return to its original state when subjected to disturbance(s) [9]. There are three types of stability: Steady State Stability, Transient Stability and Dynamic Stability [10]. Steady State stability is actually restricted to small change, i.e. bus voltage should be close to their nominal value. Transient Stability refers to large disturbance(s) after which a system Corresponding author: Hafiz Farhaj Khan returns to its original state, otherwise that system may get unstable [11]. If the changes are continuous and after each the system maintains synchronism, this is referred as Dynamic Stability, also called Small Signal Stability [12]. Steady State Stability is a function of only an operating point whereas, Transient Stability is a function of both initial condition and the State when a disturbance occurs [13].

Load is increasing day by day, but the generation and transmission system is old. To resolve this issue of overburdened transmission line and increasing load, increasing power generation and up gradation of transmission lines may be useful, but both methods are not informal and beneficial [15]. One important part that should be integrated during the electric power system's design is Transient Stability analysis. Transient Stability is the ability of the system to maintain synchronism when subjected to transient disturbance(s) [16]. Transient disturbances/faults in a power system occur due to following reasons:

- Large excursion of generator rotor angle

- Loss of load

- Loss of generator

- Short circuit fault on transmission line

- Large change in load

- Loss of transmission network from the system [17]

Transient analysis of the IEEE 9 bus system was studied in [16], where the settling of the generator's response is shown to be very short which is not practical. Moreover there is no information of fault's location in the response of generator's rotor angle and one cannot judge the location of fault by merely seeing the response of the respective generator. MATLAB/Simulink was used for the analysis of the IEEE 9 bus system, where transfer function blocks were used for the formulation of the system, which is a very lengthy process. Power flow analysis of weekly meshed distribution system was 
conducted in [18], but no conclusion is drawn from the response of the generators.

In this work, MATLAB Simpower system toolbox is used for the formulation of the IEEE 9 bus system providing block representation of non-linear systems instead of the lengthy coding or transfer function.

\section{METHODOLOGY}

The IEEE-9 bus system model was developed using MATLAB Simpower toolbox and load flow analysis of the developed system was carried out. The system was tested under normal and abnormal operating conditions. The developed system was investigated/tested for deviations in rotor angle, speed, and terminal voltages of three generators with different locations of fault.

\section{A. Mathematical Equations of the Developed System}

Under normal operating condition, the relative position of rotor axis and the resultant magnetic is fi and the difference between them is zero. The angle between these two is called power angle or torque angle $\theta_{\mathrm{m}}$ [19]. When a machine is subjected to a disturbance, the power angle is created and has positive or negative value and the rotor will accelerate or decelerate with respect to synchronously rotating air gap MMF [20]. In order to describe this phenomenon, swing equation is used. Its graph between $P_{e}$ and $\delta$ is elaborated in [22]. If $\tau_{\mathrm{e}}$ is the electrical output in the form of torque and $\tau_{\mathrm{m}}$ is the mechanical input torque, then during normal operation, the difference between them is zero, i.e $\tau_{\mathrm{e}}=\tau_{\mathrm{m}}$. When the disturbance occurs, a difference is created between them and is denoted by $\tau_{\mathrm{a}}$. Swing equation can be written as in [17]:

$$
\mathrm{J}_{0} \frac{\mathrm{d}^{2} \theta_{\mathrm{m}}}{\mathrm{dt}^{2}}=\tau_{\mathrm{a}}=\tau_{\mathrm{e}}-\tau_{\mathrm{m}}
$$

where $\mathbf{J}_{0}$ is the total moment of inertia in $\mathrm{kg} / \mathrm{m}^{2}, \theta_{\mathrm{m}}$ is the angular displacement of rotor with respect to a stationary axis in mechanical radians, $\tau_{\mathrm{a}}$ is the accelerating torque in $\mathrm{N} / \mathrm{m}$.

If $\theta_{\mathrm{m}}$ is rotating with respect to synchronously revolving frame then it can be written as:

$$
\theta_{\mathrm{m}}=\omega_{\mathrm{sm}} \mathrm{t}+\delta_{\mathrm{m}}
$$

where $\omega_{\mathrm{sm}}$ is the synchronous speed of the machine in mechanical radians per sec and $\delta_{\mathrm{m}}$ is the angular displacement of the rotor in mechanical radians from the synchronously rotating reference axis. Electrical torque $\tau_{\mathrm{e}}$ can be converted into electrical power by multiplying with $\omega$ and swing equation can be written as:

$$
\frac{2 \mathrm{H}}{\omega_{\mathrm{e}}} \frac{\mathrm{d}^{2} \delta_{\mathrm{m}}}{\mathrm{dt}^{2}}=\mathrm{P}_{\mathrm{a}(\mathrm{p} . \mathrm{u})}=\mathrm{P}_{\mathrm{e}(\mathrm{p} . \mathrm{u})}-\mathrm{P}_{\mathrm{m}(\mathrm{p} . \mathrm{u})}
$$

where $\mathrm{H}$ is the inertia constant which is the ratio between the stored kinetic energy in mega Joules at synchronous speed and machine rating in MVA.

Electrical power transfer from one point to another is can be written as:

$$
\mathrm{P}_{\mathrm{e}}=\mathrm{P}_{\max } \sin \left(\delta_{\mathrm{m}}\right)
$$

where $\mathrm{P}_{\max }$ is the maximum power output in Watts.

Graphically, we can represent swing equation (swing curve). We can write a swing equation for our test system which is the IEEE 9 bus system. The generalized form of the multi machine swing equation can be written as [22]:

$$
\begin{aligned}
& \frac{H}{\pi f_{0}} \frac{d^{2} \delta_{i}}{{d t^{2}}^{2}}=P_{m i}-\sum_{j=1}^{m}\left|E_{i}^{\prime}\right|\left|E_{j}^{\prime}\right|\left|Y_{i j}\right| \operatorname{Cos}\left(\theta_{i j}-\delta_{i}-\delta_{j}\right) \\
& =P_{m i}-P_{e i}
\end{aligned}
$$

where $E_{i}^{\prime}$ is the internal voltage of generators, $E_{j}^{\prime}$ is the voltage behind transient reactance, $\delta_{\mathrm{i}}$ is the angle of $\mathrm{E}_{\mathrm{i}}^{\prime}$ with respect to $E_{j}^{\prime}$ and $\delta_{j}$ is the angle of $E_{j}^{\prime} . Y_{i j}$ is the $Y_{\text {bus }}$ matrix of the system.

After the fault is cleared, the system returns to a new operating point and the new rotor angle at new operation point is written as [23]:

$$
\delta_{0}^{\prime}=\sin \frac{\mathrm{P}_{\mathrm{m}}}{\mathrm{P}_{\max }}
$$

\section{B. Test System}

A single line diagram of the IEEE 9 bus system can be seen in [16]. The test system is developed using MATLAB Simpower system toolbox as shown in Figure 1. IEEE 9 bus system has standard parameters like bus voltages, angle, active and reactive power at all 9 buses. There are three generator buses 1, 2 and 3 and three load buses 5,6 and 8. Generator 1, which is larger in size, is connected to slack/swing bus and generators 2 and 3 are connected to the PV bus. The three generators are producing 567MVA and the total load is 321 .

\section{Load Flow Analysis}

Load flow analysis is necessary in order to investigate the transient stability of any system [24]. It is also necessary to determine pre-fault conditions like voltage, its angle, active power, reactive power, and other variables being specified on every bus in the system [25]. The practical method of load flow study is the Newton Raphson Method [26]. In planning stages, power flow study is very important for new networks and additions to an existing network for in order to meet the increasing load demand. Load flow of the developed system is carried out so that system should not operate close to their voltage static stability [27-28].

TABLE I. BUS CLASSIFICATION [16]

\begin{tabular}{|c|c|}
\hline Bus No. & Bus Type \\
\hline 1 & Slack/Swing Bus \\
\hline 2 & PV Bus \\
\hline 3 & PV Bus \\
\hline 4 & Transformer \\
\hline 5 & Load (B) Bus \\
\hline 6 & Load (C) Bus \\
\hline 7 & Transformer \\
\hline 8 & Load (A) Bus \\
\hline 9 & Transformer \\
\hline
\end{tabular}




\section{SIMULATION RESULTS AND DISCUSSION}

Tables I-II show the load flow analysis of the IEEE 9 bus system for predetermined values of voltage, phase, and active and reactive powers. Bus 1 is a slack/swing bus, because generator 1 is the largest generator with a capacity of $247 \mathrm{MW}$. Buses 2 and 3 are PV buses because we are required to know the active and reactive power supplied by the respective generators. After load flow analysis, voltage at each bus, their angles, active and reactive power are shown in Table II. Specification of fault can be seen in Table III. All simulations are completed in MATLAB Simpower system toolbox, which is very informal to use because it contains block diagram representation of non-linear components. In order to study transient stability, a three phase fault is introduced at different locations and the response is observed. Three phase balanced fault occurred at $5 \mathrm{~s}$ and was cleared at $5.08 \mathrm{~s}$. Fault clearing time was $0.08 \mathrm{~s}$ and after that, the system was stable. With different locations of fault, rotor angle, speed and terminal voltages of three generators were investigated. When there was no fault at any bus as shown in Figures 2-4, the rotor angle deviated first to a point $-90^{\circ}$ for generator $1,-30^{\circ}$ for generator 2 and $-35^{\circ}$ for generator 3 . After that, the response was smooth and no deviation was observed until the end and the system remained stable. Generator's terminal voltage (VT) was at 1 p.u. when the system was stable.

TABLE II. LOAD FLOW ANALYSIS

\begin{tabular}{|c|c|c|c|c|}
\hline Bus No. & Voltage (p.u.) & VAngle ( & P (MW) & Q (Mvar) \\
\hline 1 & 1.0400 & 0.00 & 72.19 & 26.80 \\
\hline 2 & 1.0250 & 9.17 & 163.00 & 6.69 \\
\hline 3 & 1.0250 & 4.56 & 85.00 & -10.78 \\
\hline 4 & 1.0261 & 27.77 & 0.00 & 0.00 \\
\hline 5 & 0.9962 & 26.00 & 125.00 & 50.00 \\
\hline 6 & 1.0131 & 26.30 & 90.00 & 30.00 \\
\hline 7 & 1.0259 & 33.63 & 0.00 & 0.00 \\
\hline 8 & 1.0160 & 30.63 & 100.00 & 35.00 \\
\hline 9 & 1.0324 & 31.87 & 0.00 & 0.00 \\
\hline
\end{tabular}

TABLE III. FAULT SPECIFICATIONS

\begin{tabular}{|c|c|}
\hline Components & Value \\
\hline Fault Resistance $(\mathrm{Ohm})$ & 5 \\
\hline Ground Resistance $(\mathrm{Ohm})$ & 0.001 \\
\hline Snubber Resistance $(\mathrm{Ohm})$ & $1 \times 10^{6}$ \\
\hline Snubber Capacitance (Farad) & $\mathrm{Inf}$ \\
\hline
\end{tabular}

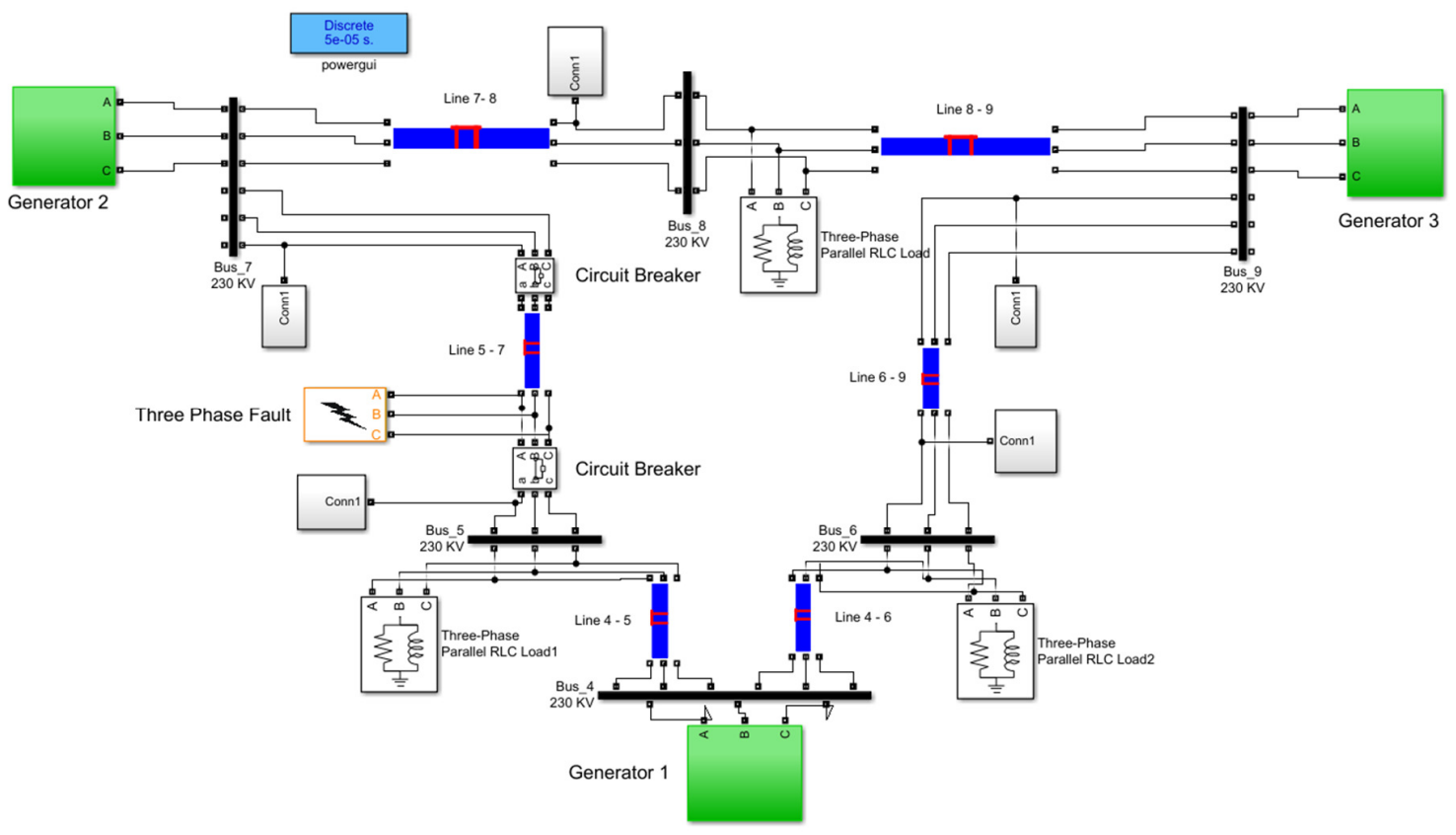

Fig. 1. Simulation diagram of the test system

\section{A. Response of Generators without Fault}

The response of deviation in rotor angle, speed and the terminal voltages of all generators without fault are shown in Figures 2-4.

\section{B. Fault at Bus 1 (Swing Bus)}

The response of deviation in rotor angle, speed, and terminal voltages of all generators with fault at bus 1 are shown in Figures 5-7.

\section{Fault at Generator 2 (PV Bus 1)}

The response of deviation in rotor angle, speed, and terminal voltages of all generators with fault at bus 3 are shown in Figures 8-10.

\section{Fault at Generator 3 (PV Bus 2)}

The response of deviation in rotor angle, speed, and terminal voltages of all generators with fault at bus 3 are shown in Figures 11-13.

\section{E. Fault between Buses 5 and 7}

The response of deviation in rotor angle, speed, and terminal voltages of all generators with fault between buses 5 and 7 are shown in Figures 14-16. 


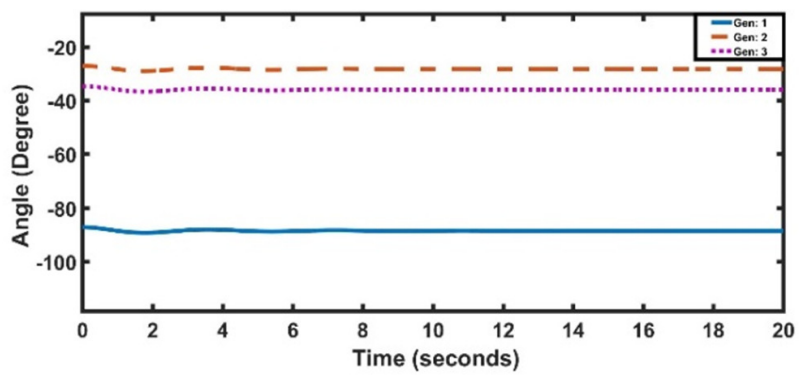

Fig. 2. Deviation in rotor angle without fault

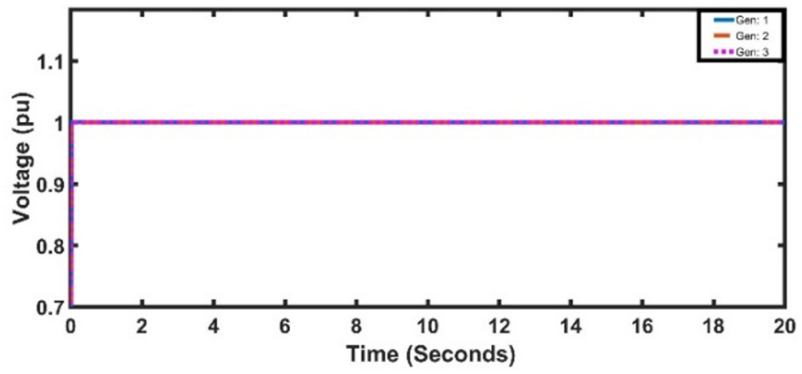

Fig. 3. Generator speed of generators without fault

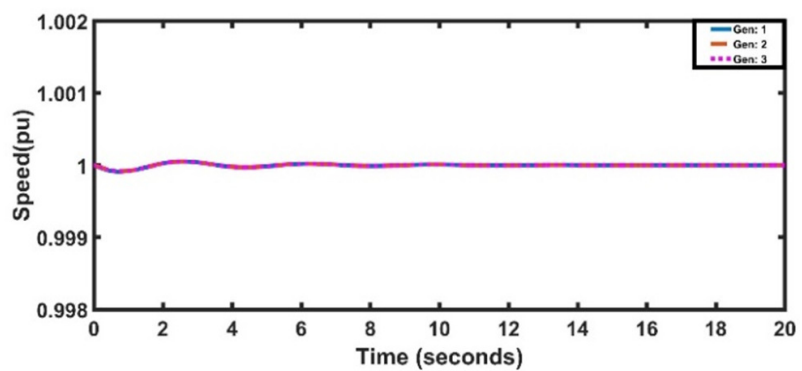

Fig. 4. Terminal voltage without fault

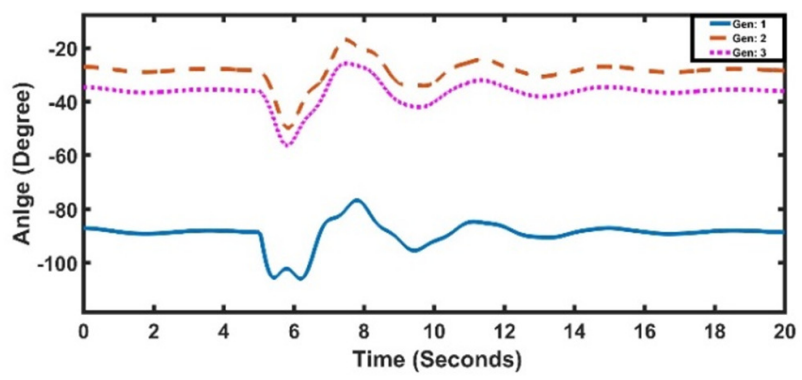

Fig. 5. Deviation in rotor angle with fault at bus 1

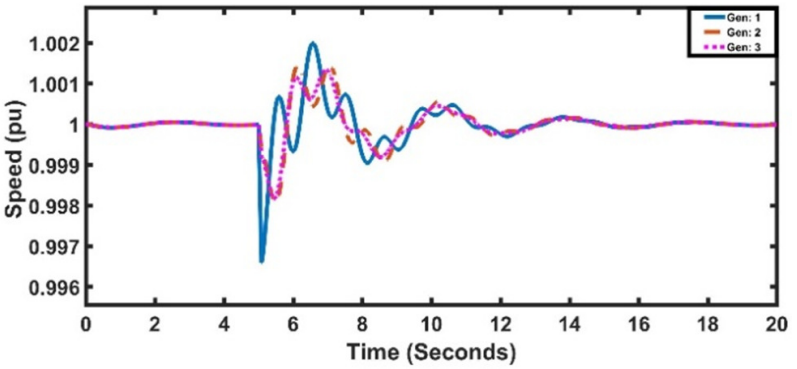

Fig. 6. Rotor speed with fault at bus 1

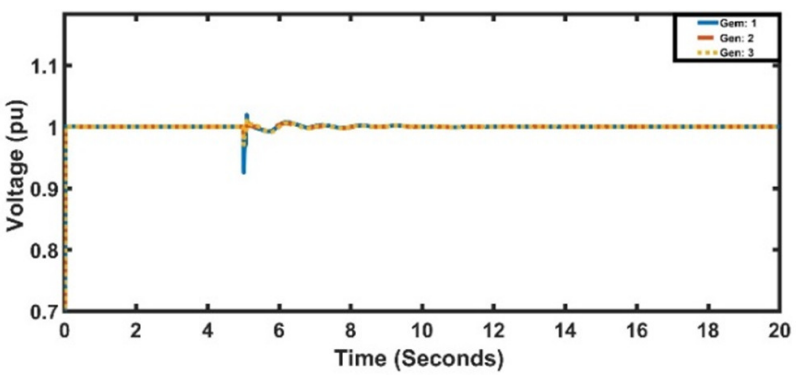

Fig. 7. Terminal voltage with fault at bus 1

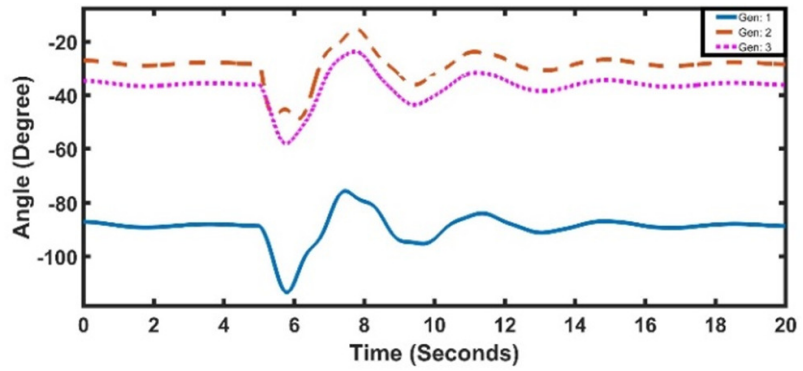

Fig. 8. Deviation in rotor angle with fault at bus 2

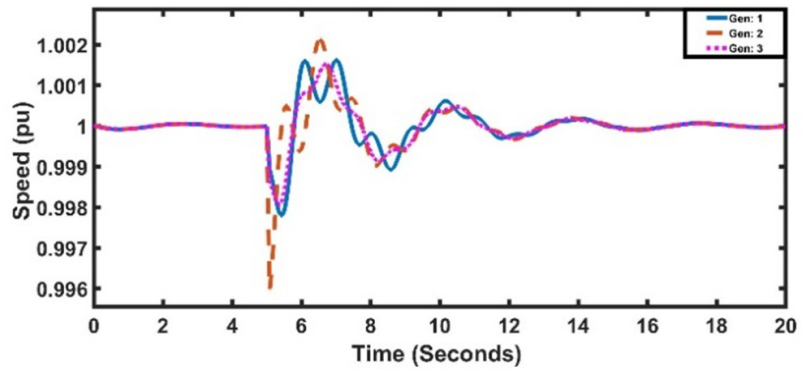

Fig. 9. Rotor speed with fault at bus 2

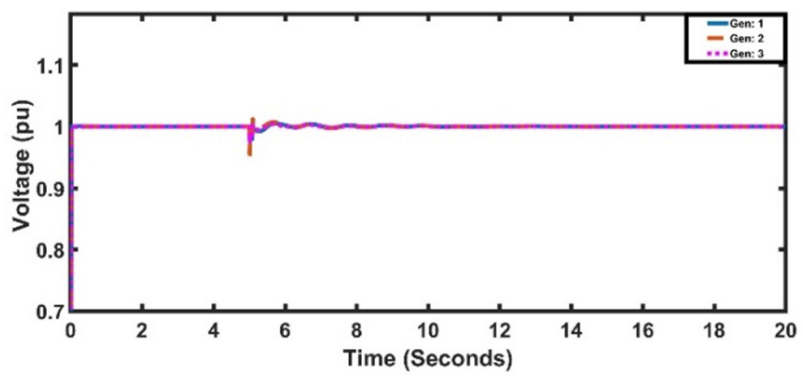

Fig. 10. Terminal voltage with fault at bus 2

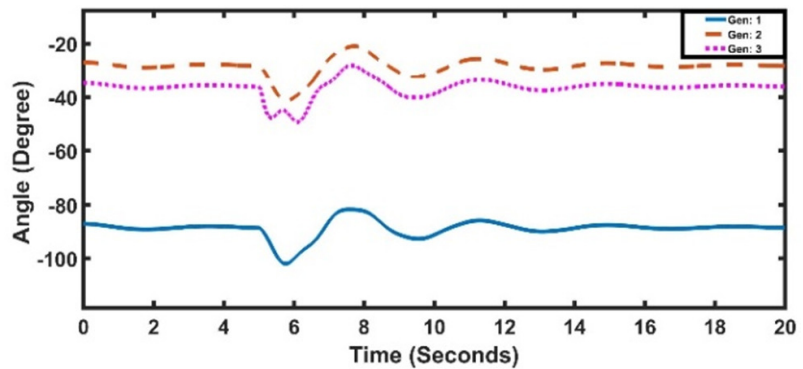

Fig. 11. Deviation in rotor angle with fault at bus 3 


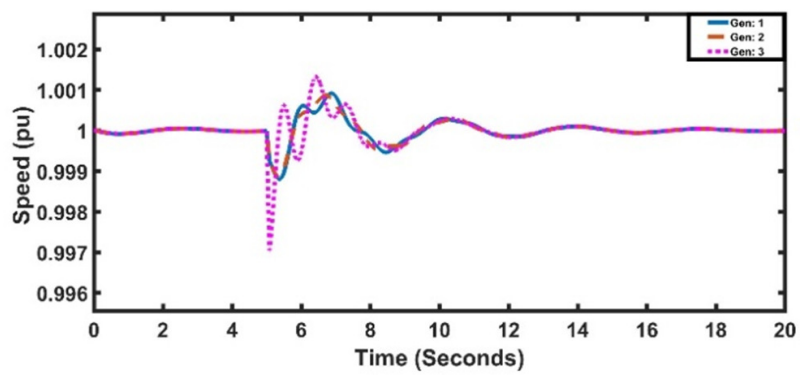

Fig. 12. Rotor speed with fault at bus 3

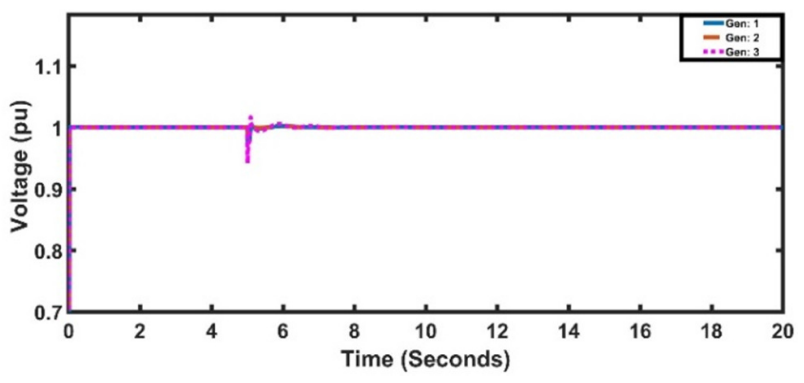

Fig. 13. Terminal voltage with fault at bus 3

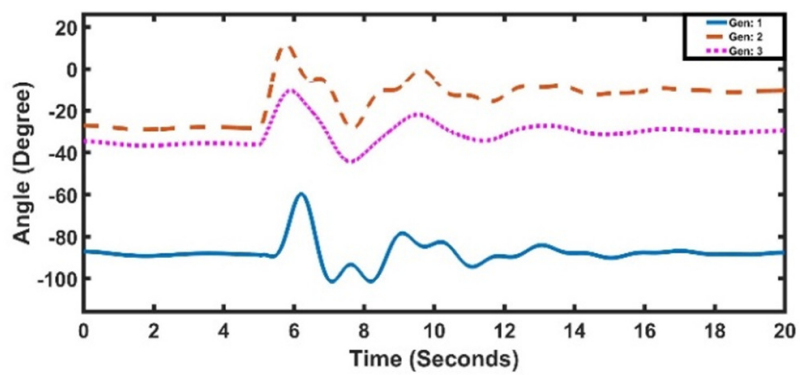

Fig. 14. Deviation in rotor angle with fault between bus 5 and 7

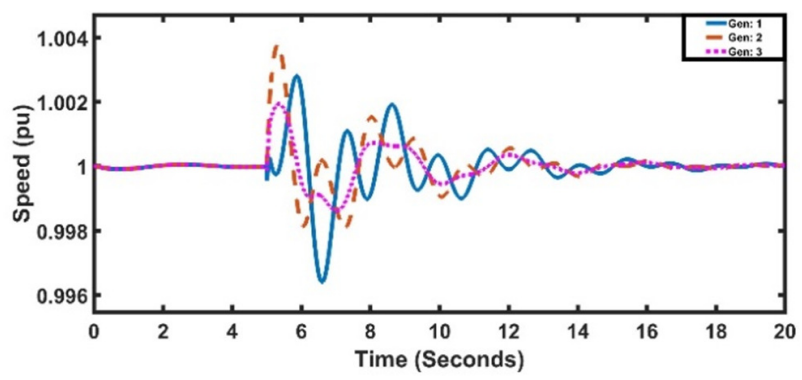

Fig. 15. Rotor speed with fault between bus 5 and 7

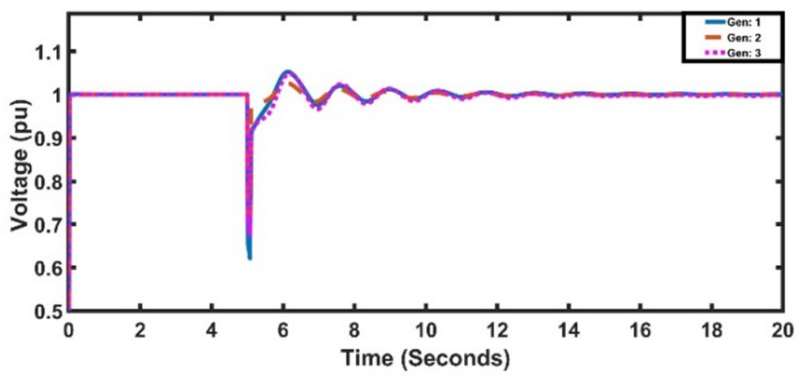

Fig. 16. Terminal voltage with fault between bus 5 and 7
When a three phase fault is introduced at bus 1 or generator 1 , distortion in the response of all generators can be seen in Figures 5-7. At first the rotor angle is at equilibrium point, but when fault occurred, oscillations were formed and after some time, they were damped out and vanished. A characteristic double hump can be easily observed in the rotor angle of generator 1 . Because fault is nearest to the generator 1 , a double hump was introduced in response of generator 1 . In Figures 6 and 7, generator's speed and terminal voltage is exhibited. The largest distortion can be seen in the response of generator 1 , because the fault is nearest to generator 1 . Generators 2 and 3 are less effective, because they are far away from the location of the fault.

When a three phase fault was introduced at buses 2 and 3 , the response can be seen in Figures 8 and 11. It is observed that, after the fault is cleared, the system takes its own time to return to a new equilibrium point. In our case, after the clearance of fault, the system takes $16 \mathrm{~s}$ to return to a new equilibrium point. Transient stability analysis of IEEE 9 bus system is done in [12] but nothing can be concluded from the response of generators. In this work, the location of fault can be predicted by looking at the response of the generator, because fault prediction in a large power system is difficult. Sensitive components cannot bear too much time of oscillations, that's why this settling time can be decreased by using FACT devices like DSTACOM, power system stabilizers, etc. [29-31].

The response of introducing fault was between buses 5 and 7 is shown in Figures 14-16. In this case, because the fault occurred between generators 2 and 3 , oscillations and characteristic hump were noted in the response of generators 2 and 3, but more oscillations can be observed in the response of generator 1 , because it is nearer to the location of the fault than generator 2 .

\section{CONCLUSION}

A complete model for transient stability of a 9 bus IEEE system with 3 generators was developed and tested using Matlab/Simulink Simpower system toolbox. The behavior of a three phase balanced fault with different locations was investigated. It is concluded that, the system takes some time to stabilize, i.e. it reaches a peak value and after that it decays to its final or steady state value. A three phase fault was introduced at $5 \mathrm{~s}$, and the system took some time to get stable. It was also determined that fault location is also important in order to analyze the stability of the system. Fault location can be deduced by looking at the response of the generator. Further, fault clearing time must be very short. In order to reduce settling time, FACT devices like power system stabilizers, dynamic voltage restorer (DVR), DSTATCOM, etc. can be used to increase the stability of the system and reduce the system's settling time preventing damage to sensitive equipment.

\section{REFERENCES}

[1] S. A. Nasar, F. C. Trutt, Electric power systems, CRC Press, 1998

[2] Y. Zhong, S. Huang, D. Luo, "Stabilization and speed control of a permanent magnet synchronous motor with dual-rotating rotors", Energies, Vol. 11, No. 10, Article ID 2786, 2018 
[3] E. A. Androulidakis, A. T. Alexandridis, H. E. Psillakis, D. P. Agoris, "Challenges and trends of restructuring power systems due to deregulation", 5th WSEAS International Conference on Power Systems and Electromagnetic Compatibility, Corfu, Greece, August 23-25, 2005

[4] H. H. Alhelou, M. E. H. Golshan, E. H. Forushani, A. S. A. Sumaiti, P. Siano, "Decentralized fractional order control scheme for LFC of deregulated nonlinear power systems in presence of EVs and RER", International Conference on Smart Energy Systems and Technologies, Seville, Spain, September 10-12, 2018

[5] S. K. Mahapatro, "Transient stability analysis in interconnected power system for power quality improvement", International Journal of Engineering Research and Technology, Vol. 2, No. 2, pp. 1-12, 2013

[6] M. Li, P. Jiang, W. Wu, R. Ye, Y. Du, H. Zheng, T. Yan, “Artificial neural network classifier of transient stability based on time-domain simulation", 2nd IEEE Advanced Information Management, Communicates, Electronic and Automation Control Conference, Xi'an, China, May 25-27, 2018

[7] H. H. Alhelou, M. E. H. Golshan, T. C. Njenda, P. Siano, "A survey on power system blackout and cascading events: Research, motivations and challenges”, Energies, Vol. 12, No. 4, Article ID 682, 2019

[8] P. Kundur, Power system stability and control, McGraw-Hill Education, 1994

[9] J. A. Momoh, M. E. E. Hawary, Electric systems, dynamics, and stability with artificial intelligence applications, CRC Press, 2018

[10] A. Halder, N. Pal, D. Mondal, "Transient stability analysis of a multimachine power system with TCSC controller: A zero dynamic design approach", International Journal of Electrical Power \& Energy Systems, Vol. 97, pp. 51-71, 2018

[11] M. Tacchi, B. Marinescu, M. Anghel, S. Kundu, S. Benahmed, C. Cardozo, "Power system transient stability analysis using sum of squares programming", Power Systems Computation Conference, Dublin, Ireland, June 11-15, 2018

[12] R. Kaur, E. D. Kimar, "Transient stability analysis of IEEE 9 bus system in power world simulator", International Journal of Engineering Research and Applications, Vol. 6, No. 1, pp. 35-39, 2016.

[13] B. Wang, K. Sun, "Formulation and characterization of power system electromechanical oscillations", IEEE Transactions on Power Systems, Vol. 31, No. 6, pp. 5082-5093, 2016

[14] I. A. Calle, Transient stability constrained optimal power flow: Improved models and practical applications, $\mathrm{PhD}$ Thesis, Universidad Carlos III de Madrid, 2015

[15] R. Manickam, S. N. Palaniappan, "Upgrading transmission line capability by AC-DC conversion", Computers \& Electrical Engineering, Vol. 68, pp. 616-628, 2018

[16] R. Patrik, R. Shrikhande, S. Kamdi, "Transient stability analysis of IEEE-9 bus electrical power system", International Journal of Engineering And Computer Science, Vol. 6, No. 4, pp. 20847-20850, 2017

[17] R. Patel, T. S. Bhatti, D. P. Kothari, "Study of power system transient stability with simulink", National Power Systems Conference, Kharagpur, India, December 27-29, 2002

[18] A. A. Sakkaf, M. AlMuhaini, "Power flow analysis of weakly meshed distribution network including DG", Engineering, Technology \& Applied Science Research, Vol. 8, No. 5, pp. 3398-3404, 2018

[19] A. Sajadi, R. Preece, J. V. Milanovic, "Establishment multidimensional transient stability boundaries for power systems with uncertainties", Power Systems Computation Conference, Dublin, Ireland, June 11-15, 2018

[20] J. Cepeda, P. Salazar, D. Echeverria, H. Arcos, "Implementation of the single machine equivalent (SIME) method for transient stability assessment in DIgSILENT Powerfactory, Springer, 2018

[21] Gulvender, P. Dash, "Study on mathematical modeling of power system stability analysis", International Journal of Advanced Research in Electrical, Electronics and Instrumentation Engineering, Vol. 5, No. 6, pp. 5670-5676, 2016

[22] P. Basu, A. Harichandan, Power system stability studies using Matlab, BSc Thesis, National Institute of Technology Rourkela, 2009
[23] T. Sweidan, I. M. Abuashour, M. M. Hattab, M. A. Ma'itah, "Numerical simulations for transient stability analysis of two-machine power system considering three-phase fault under different fault clearing times and locations”, Energy and Power, Vol. 7, No. 1, pp. 22-36, 2017

[24] I. B. Sulistiawati, K. M. Rosidin, A. Lomi, "Dynamic stability modified IEEE 3 generator 9 bus with $50 \mathrm{mw}$ power injection of generator xy", International Seminar on Intelligent Technology and Its Application, Surabaya, Indonesia, August 28-29, 2017

[25] L. Wang, A. A. Girgis, "A new method for power system transient instability detection", IEEE Transactions on Power Delivery, Vol. 12, No. 3, pp.1082-1089, 1997

[26] B. Sereeter, C. Vuik, C. Witteveen, "On a comparison of NewtonRaphson solvers for power flow problems", Journal of Computational and Applied Mathematics, Vol. 360, pp. 157-169, 2019

[27] P. Yu, B. Venkatesh, A. Yazdani, B. N. Singh, "Optimal location and sizing of fault current limiters in mesh networks using iterative mixed integer nonlinear programming", IEEE Transactions on Power Systems, Vol. 31, No. 6, pp. 4776-4783, 2016

[28] C. L. Wadhwa, Electrical Power Systems, New Age International, 5th ed., 2009

[29] P. P. Panchbhai, P. S.Vaidya, "Transient stability improvement of IEEE 9 bus system with shunt facts device statcom", International Research Journal of Engineering and Technology, Vol. 3, No. 3, pp. 128-132, 2016

[30] R. Rangu, P. Upadhyay, "Study of transient stability improvement of IEEE 9-bus system by using svc", International Journal of Engineering Trends and Technology, Vol. 27, No. 3, pp. 162-166, 2015

[31] G. Shahgholian, E. Mardani, A. Fattollahi, "Impact of PSS and STATCOM devices to the dynamic performance of a multi-machine power system", Engineering, Technology \& Applied Science Research, Vol. 7, No. 6, pp. 2113-2117, 2017 